\title{
MARS: OCCURRENCE OF LIQUID WATER
}

\author{
ANDREW P. INGERSOLL \\ Division of Geological Sciences, California Institute of Technology, Pasadena, Calif., U.S.A.
}

\begin{abstract}
In the absence of juvenile liquid water, condensation and subsequent melting of ice are the only means of producing liquid water on the Martian surface. However, the evaporation rate is so high that the available heat sources cannot melt ice on Mars. Melting might occur only in concentrated solutions of strongly deliquescent salts.
\end{abstract}

The purpose of this study is to see whether sunlight or other heat sources can melt water ice on Mars; this is probably the most likely mechanism by which liquid water might naturally occur on the Martian surface. If all the water were to condense out of the atmosphere, it would cover the surface with a layer 10 to $20 \mu \mathrm{m}$ thick (Kaplan et al., 1964; Owen and Mason, 1969). On the other hand, if this amount were mixed uniformly with other atmospheric gases, condensation would occur at temperatures in the range 190 to $200 \mathrm{~K}$ (Leighton and Murray, 1966). This means that only ice will condense directly out of the atmosphere, and also that frosts at temperatures above $200 \mathrm{~K}$ will cool by evaporation unless there is an adequate heat source. Thus, the circumstances most favorable to melting are when the rate of evaporation of a frost at $0{ }^{\circ} \mathrm{C}$ is at its minimum.

In order to estimate this minimum rate, we shall assume there is no wind, and that the only atmospheric motions are those generated by the evaporation itself. However, water vapor is intrinsically lighter than carbon dioxide, the principal constituent of the Martian atmosphere, and so the saturated fluid layer near the ground is dynamically unstable. The situation is analogous to thermal convection above a heated horizontal surface, and therefore we shall use thermal convection data to estimate the evaporation rate.

The similarity between heat convection and mass exchange is described in many engineering textbooks (Jakob, 1949). It is based on the similarity of the equations for conservation of heat and diffusing substance, respectively, in a moving fluid, and on the fact that a smaller molecular weight has the same effect on buoyancy as a correspondingly higher temperature. The analogy is not exact, however, but the error leads to our underestimating the evaporative loss. In the first place, evaporation implies a velocity normal to the wall, for which there is no analogue in thermal convection. This normal velocity carries additional mass, so the evaporation rate should be greater than that estimated from the thermal convection analogy (Eckert and Drake, 1959). Second, when concentration gradients are large, the analogy fails because of thermal diffusion effects. Again this leads to underestimating the evaporation rate, since heat tends to diffuse toward fluid of lower molecular weight (Chapman and Cowling, 1939), thereby increasing the instability of the system.

Thus the estimate which follows will be a lower bound on the evaporation rate of 
water ice on Mars. The basic experimental data are measurements of heat flux above a heated horizontal plate in air as a function of the physical properties of air and the temperature difference between the plate and its surroundings. Using these data (Jakob, 1949) and the thermal convection analogy, we obtain

$$
E=(0.17) \Delta \eta \rho D\left[(\Delta \rho / \rho) g / \nu^{2}\right]^{1 / 3},
$$

for the mass flux of water vapor $E$ above an evaporating frost. Here $\Delta \eta$ is the difference between the mass concentration of water vapor at the evaporating surface and in the gas away from the surface. Since the fluid is saturated near the frost (at temperature $T_{0}$ ), and since the surroundings are almost completely dry, we have

$$
\Delta \eta=\rho_{w}\left(T_{0}\right) / \rho,
$$

where $\rho_{w}\left(T_{0}\right)$ is the saturation density of water vapor and $\rho$ is the total density of the gas at the surface. The quantity $D$ is the diffusion coefficient of water vapor in carbon dioxide; $g$ is the acceleration of gravity on Mars; and $\nu$ is the kinematic viscosity of carbon dioxide. Finally, $(\Delta \rho / \rho)$ is the density difference between the ambient fluid and the fluid at the surface, divided by the density of the fluid at the surface. This may be expressed in terms of the Martian surface pressure $P_{0}$ and the saturation vapor pressure of water $e=e\left(T_{0}\right)$, provided both components of the mixture behave as ideal gases:

$$
\Delta \rho / \rho=\left(m_{c}-m_{w}\right) e /\left[m_{c} P_{0}-\left(m_{c}-m_{w}\right) e\right],
$$

where $m_{w}$ and $m_{c}$ are the molecular weights of water and carbon dioxide, respectively. In this derivation the change in pressure across the saturated boundary layer is neglected; this is valid provided the layer is thin compared to the atmospheric scale height $H=R T / g$, where $R$ is the gas constant of the atmosphere.

Combining these equations, and multiplying by the heat of vaporization of ice $\lambda$, we obtain an expression for $\lambda E$, the rate of heat loss of a frost at temperature $T_{0}$ in a carbon dioxide atmosphere at pressure $P_{0}$. These results are presented in Table I, and

TABLE I

Heat fluxes $\left(\mathrm{cal} / \mathrm{cm}^{2} / \mathrm{min}\right)$ necessary to maintain an evaporating frost deposit at constant temperature, for various temperatures and pressures

\begin{tabular}{lllll}
\hline Temperature & \multicolumn{4}{l}{ Surface pressure $P_{0}(\mathrm{mb})$} \\
\cline { 2 - 5 }$T_{0}$ & 6 & 10 & 15 & 25 \\
\hline$\left.{ }^{\circ} \mathrm{C}\right)$ & & & & \\
\hline 0 & 1.25 & 0.76 & 0.55 & 0.38 \\
-5 & 0.62 & 0.41 & 0.30 & 0.21 \\
-10 & 0.33 & 0.22 & 0.17 & 0.12 \\
\hline
\end{tabular}

are based on published values of the gravitational acceleration on Mars, the vapor pressure and heat of vaporization of ice, the viscosity of carbon dioxide, and the mass diffusivity of water vapor in carbon dioxide (Boynton and Brattain, 1929). It is seen 
that the rate of evaporation, and hence the necessary heat flux, varies directly as the partial pressure of water vapor, and inversely as the Martian surface pressure.

From these data, the most favorable sites for the occurrence of liquid water are those at low elevations where the surface pressure is high. Slopes which face the sun directly during part of the day are also favored. However, the solar constant at the orbit of Mars is about $0.85 \mathrm{cal} / \mathrm{cm}^{2} / \mathrm{min}$, and the mean surface pressure is about 5-7 mb (Kliore et al., 1965; Kliore, 1971). Even at the lowest points, the pressure is probably less than $10 \mathrm{mb}$ (Belton and Hunten, 1969), and since the albedo of frost is high, it appears that water ice may never melt on the Martian surface. Under these circumstances, a frost exposed to sunlight simply evaporates at a temperature below the melting point when exposed to sunlight.

A separate issue concerns the lifetime of a frost of typical thickness compared to the time necessary to melt it. Even if all the atmospheric water vapor were to condense out during the Martian night, the morning frost layer would be only 10-20 $\mu \mathrm{m}$ thick. From Table I with $\lambda=676 \mathrm{cal} / \mathrm{gm}$, the lifetime of such a frost at $-10{ }^{\circ} \mathrm{C}$ would be several minutes, and since the frost is likely to spend more time than this in warming from $-10{ }^{\circ} \mathrm{C}$ to $0{ }^{\circ} \mathrm{C}$, it will probably disappear before the temperature reaches the melting point. The situation is more favorable at the polar caps, where larger amounts of frost might accumulate during the Martian winter (Leighton and Murray, 1966). However, the solar heating is also more gradual at the poles, following an annual rather than a daily cycle, so the frost lifetime is still short compared to the time necessary to heat the frost.

Another possibility concerns the melting of water in soil interstices (Sagan et al., 1968), where evaporation is slowed by the close packing of soil above the melting level. Let us assume that this water collects by freezing, and must diffuse down from the atmosphere during the night. Then, since the partial pressure of water in the atmosphere is some $10^{-4}$ times the vapor pressure at $-10^{\circ} \mathrm{C}$, the lifetime of the accumulated deposit at $-10^{\circ} \mathrm{C}$, will be only $10^{-4}$ times the accumulation time. This lifetime is about $\frac{1}{2} \mathrm{~h}$ at the pole and $10 \mathrm{sec}$ elsewhere, so this mechanism does not increase the likelihood of melting.

Note that this argument applies when the only source of water is the atmosphere. Liquid water from the interior of the planet might occasionally reach the surface to form hot springs (Sagan et al., 1968), although there is no indication that such a process occurs on the earth. Most evidence suggests that terrestrial hot springs contain re-cycled rain water (Mason, 1966), although small amounts of juvenile water may also be present.

Let us now compare the effects of wind with the effects of compositional density differences already mentioned. Measured rates of evaporation under conditions of neutral stability on the earth give (Priestley, 1959):

$$
E=(0.002) \rho_{w} U
$$

where $\rho_{w}$ is the saturation density of water vapor and $U$ is the wind velocity $1 \mathrm{~m}$ above the surface. However, even for $U=100 \mathrm{~m} / \mathrm{s}$, the additional evaporation due to wind is less than the rates implied in Table $I$. The opposite question is whether wind could supply the necessary heat to the surface, but here again the effect appears to be 
negligible. In fact, the turbulence necessary to mix heat downwards to the surface would also cause an increase in evaporation, leading to a net cooling. For, if $\Delta T$ is the temperature difference between the warm atmosphere and cool surface, then the flux of heat to the surface will be $\rho U_{0} c_{p} \Delta T$, where $c_{p}$ is the specific heat of the gas and $U_{0}$ is some velocity characteristic of the process. However, at the same time the evaporative cooling will be $\rho U_{0} \lambda \Delta \eta$, which is larger than the heating for all reasonable choices of parameters, for frost temperatures greater than $-10^{\circ} \mathrm{C}$.

All of the above remarks apply only to pure water ice. Dissolved salts have the effect of lowering both the melting temperature and the vapor pressure, and for certain substances these effects can be quite large. As an extreme example, $\mathrm{CaCl}_{2}$ lowers the vapor pressure by a factor of 5 , and the melting point by $50{ }^{\circ} \mathrm{C}$ (Hall and Sherrill, 1929). Under these conditions the evaporative cooling is negligible, and the lifetime is effectively infinite. Thus liquid water is possible on Mars, but it will probably occur only in concentrated solutions of strongly deliquescent salts. Pure liquid water may never occur on Mars, because the available heat sources cannot balance the evaporative cooling, and because any frost will evaporate completely before it reaches the melting point.

\section{References}

Belton, M. J. S., and Hunten, D. M.: 1969, Science 166, 225.

Bircumshaw, L. L. and Stott, V. H.: 1929, in International Critical Tables (ed. by E. W. Washburn), McGraw-Hill, New York.

Boynton, W. P. and Brattain, W. H.: 1929, in International Critical Tables (ed. by E. W. Washburn), McGraw-Hill, New York.

Chapman, S. and Cowling, T. G.: 1939, The Mathematical Theory of Non-Uniform Gases, Cambridge University Press, p. 19.

Eckert, E. R. G. and Drake, R. M., Jr.: 1959, Heat and Mass Transfer, McGraw-Hill, New York. Hall, R. E. and Sherrill, M. S.: 1929, in International Critical Tables, McGraw-Hill, New York. Jakob, M.: 1949, Heat Transfer, Vol. 1, Wiley, New York.

Kaplan, L. D., Münch, G., and Spinrad, H.: 1964, Astrophys. J. 139, 1.

Kliore, A.: 1971, in preparation.

Kliore, A., Cain, D. L., Levy, G. S., Eshelman, V. R., and Fjeldbo, C.: 1965, Science 149, 1243.

Leighton, R. B. and Murray, B. C.: 1966, Science 153, 136.

Mason, B.: 1966, Principles of Geochemistry, 3rd ed., Wiley, New York.

Owen, T. and Mason, H. P.: 1969, Science 165, 893.

Priestley, C. H. B.: 1959, Turbulent Transfer in the Lower Atmosphere, University of Chicago Press. Sagan, C., Levinthal, E. C., and Lederberg, J.: 1968, Science 159, 1191.

Spencer, H. M.: 1929, in International Critical Tables (ed. by W. E. Washburn), McGraw-Hill, New York. 